\title{
PEMANFAATAN TUMBUHAN SEBAGAI BAHAN \\ KOSMETIK OLEH MASYARAKAT SUKU \\ MANDAR KECAMATAN MAPILLI \\ KABUPATEN POLEWALI MANDAR
}

\author{
Irma Damayanti* \\ *Jurusan Biologi Fakultas Sains dan Teknologi \\ Universitas Islam Negeri (UIN) Alauddin Makassar \\ email:irmadamayanti@gmail.com
}

\begin{abstract}
Abstrak: Penggunaan tumbuhan sebagai bahan kosmetik telah dimanfaatkan oleh Masyarakat Suku Mandar Kecamatan Mapilli Kabupaten Polewali Mandar. Tujuan dari penelitian ini adalah untuk menyelidiki spesies tanaman, bagian tanaman, lokasi tanaman, dan nilai rasio kesepakatan informan pemahaman masyarakat tentang penggunaan tumbuhan untuk kosmetik alami. Untuk menentukan sampel studi, purposive sampling diterapkan dan wawancara semiterstruktur digunakan untuk mengumpulkan data. Berdasarkan penelitian studi Etnobotani, ditemukan 125 spesies tumbuhan dari empat divisi yaitu Magnoliophyta 120 spesies, Pteridophyta 3 spesies, Tracheophyta 1 spesies, Gnetophyta 1 spesies. Berdasarkan kelasnya, tumbuhan tersebut berasal dari lima kelas yaitu Liliopsida, Magnoliopsida, Pinopsida, Pteropsida, Gnetopsida yang dimanfaatkan sebagai pengobatan tradisional, bahan makanan dan penyedap, bahan bangunan, ritual adat, pewarna alami, dan kecantikan/perawatan tubuh. Salah satunya yang akan dipaparkan pada artikel ini sebagai kecantikan/perawatan tubuh yaitu 22 spesies tumbuhan dari satu divisi Magnoliphyta, dua kelas Magnoliopsida dan Liliopsida.
\end{abstract}

Kata Kunci: Etnobotani, Kosmetik, Suku Mandar, Tumbuhan

\section{PENDAHULUAN}

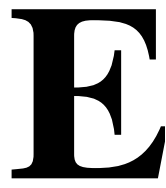

tnobotani merupakan kajian interaksi antara masyarakat, lingkungan, dalam pemanfaatan tumbuhan, mendokumentasikan pengetahuan masyarakat, keperluan ekonomi, spiritual, dan nilai budaya (Apriliani dkk., 2014; Shanthi dkk., 2014; Susanti, 2015; Cotton, 1996; Ibrahim dkk., 2012; Ajesh dkk., 2012). Kajian ilmu Etnobotani menjadi matakuliah pilihan dibeberapa universitas yang penting dipelajari, dan berhubungan dengan bidang kesehatan 
serta upaya konservasi sebagai bekal mahasiswa untuk pemanfaatan kecantikan/perawatan tubuh (Kunwar \& Bussmann, 2008). Indonesia merupakan negara yang memiliki keberagaman dalam pemanfaatan tumbuhan salah satunya suku masyarakat Kabupaten Banyuwangi yang memanfaatkan tumbuhan dalam keperluan sehari- hari tidak hanya sebagai bahan pangan, pakaian dan tempat tinggal, tetapi juga untuk upacara keagamaan, kerajinan, dan pengobatan, salah satunya kecantikan/perawatan tubuh (Pillai dkk., 2008; Uddin dkk., 2013; Walujo, 2008). Perawatan tubuh dengan menggunakan bahan alami tidak terbatas pada kulit untuk pembersih kulit, pelembab dan pelindung kulit tetapi juga bermanfaat untuk perawatan gigi, kuku, rambut, dan lain-lain (Gayatri dkk., 2015).

Kosmetik telah menjadi bagian kehidupan manusia sejak zaman dahulu. Kosmetik digunakan secara luas baik untuk kecantikan maupun untuk kesehatan. Namun, tingkat keamanan kosmetik harus tetap diperhatikan oleh para konsumen berkaitan dengan masih banyak ditemukannya produk kosmetik yang mengandung bahan berbahaya. Oleh karena itu, kosmetik alami lebih dianjurkan karena tidak menimbulkan resiko bagi kesehatan. Sedangkan, kosmetik sintetis dikhawatirkan mengandung bahan-bahan berbahaya yang dapat menimbulkan resiko bagi kesehatan, mengingat pengolahan bahan kosmetik sintetis menggunakan campuran bahan-bahan kimia.

\section{METODE}

Jenis penelitian ini adalah penelitian studi Etnobotani. Penelitian dilakukan melalui survei lapangan. Survei lapangan dilakukan melalui dua tahap yaitu metode observatif (penentuan responden) dan survei Eksploratif (kegiatan wawancara masyarakat suku Mandar berdasarkan kuesioner), wawancara dilakukan untuk memperoleh data dan informasi langsung masyarakat suku Mandar dengan menggunakan kuesioner lapangan dan wawancara semi terstruktur. Jenis data yang dikumpulkan pada penelitian ini adalah data deskriptif kuantitatif. Data deskriptif diperoleh dari hasil studi Etnobotani, pengolahan data dilakukan dengan cara menyajikan data secara deskriptif tentang Etnobotani yang meliputi pemanfaatan dan pengolahan tumbuhan. 
Irma Damayanti, Pemanfaatan Tumbuhan Sebagai Bahan Kosmetik oleh Masyarakat ..._ 13

\section{HASIL DAN PEMBAHASAN}

Berdasarkan survei yang dilakukan, ditemukan 125 spesies yang digunakan oleh masyarakat suku mandar untuk menunjang kehidupan sehari-hari, seperti: pengobatan tradisional, bahan makanan dan penyedap, bahan bangunan, ritual adat, pewarna alami, dan kecantikan/perawatan tubuh, salah satunya sebagai kecantikan/perawatan tubuh. Berikut tabulasi jenis tumbuhan bermanfaat sebagai kecantikan/perawatan tubuh dapat dilihat pada Tabel 1.

Tabel 1. Pemanfaatan Tumbuhan sebagai Kecantikan/Perawatan Tubuh

\begin{tabular}{|c|c|c|c|}
\hline $\begin{array}{l}\text { Jenis kecantikan / } \\
\text { Perawatan Tubuh }\end{array}$ & Spesies Tumbuhan & Famili & $\begin{array}{c}\text { Bagian yang } \\
\text { Digunakan }\end{array}$ \\
\hline Rias wajah & $\begin{array}{c}\text { Kemuning } \\
\text { (Murrayapaniculata) }\end{array}$ & Rutaceae & Daun \\
\hline Lulur wajah & $\begin{array}{c}\text { Kemuning } \\
\text { (Murraya paniculata) }\end{array}$ & Rutaceae & Daun \\
\hline Bedak dingin & $\begin{array}{c}\text { Padi } \\
\text { (Oryza sativa L.) }\end{array}$ & Poaceae & Bulir \\
\hline Perawatan & $\begin{array}{l}\text { Jeruk nipis } \\
\text { (Citrus) }\end{array}$ & Rutaceae & Buah \\
\hline $\begin{array}{l}\text { Menghilangkan flek } \\
\text { hitam di wajah }\end{array}$ & $\begin{array}{c}\text { Pinang } \\
(\text { Areca catechu L.) }\end{array}$ & Arecaceae & Kulit \\
\hline Menghaluskan wajah & $\begin{array}{c}\text { Santan } \\
\text { (Kibatalia arborea) }\end{array}$ & Apocynaceae & Daun \\
\hline Perawatan gigi & $\begin{array}{c}\text { Pinang } \\
(\text { Areca catech } \mathrm{L} .)\end{array}$ & Arecaceae & Buah \\
\hline
\end{tabular}

Berdasarkan hasil survei Etnobotani diketahui 125 spesies tumbuhan yang dimanfaatkanoleh masyarakat Suku Mandar Kecamatan Mapilli Kabupaten Polewali Mandar dalam kehidupan sehari-hari sebagai pengobatan tradisional, bahan makanan dan penyedap, bahan bangunan, ritual adat, pewarna alami, dan kecantikan/perawatan tubuh. Salah satunya terdapat 22 spesies yang dimanfaatkan sebagai bahan kecantikan/perawatan tubuh yang sampai saat ini masih dilakukan, antara lain, Jeruk Purut (Jeruk Purut; Citrus hystrix DC), Kemuning (Kemuning; Murraya paniculata L.Â Jack), Kencur (Kencur; Kaempferia galanga L.), Padi (Pari; Oryza sativa L.), Pinang (Jambe; Areca catechu L.), Kunyit (Kunir; Curcuma longa L.), Asem (Asem; Tamarindus Indica L.), Majakan (Majakan; Quercus lusitanica), Kunci (Kunci; Boesenbergia rotunda (L.) Mansf.), Gambir 
(Gambir; Uncaria gambir (Hunter) Roxb.), Sirih (Suruh; Piper betle L.), Santan (Santen; Kibatalia arborea (Blume) G. Don), Kangkung (Kangkung; Ipomoea aquatica Forssk.), Lansat (Langsep; Lansium domesticum Corrêa), Pepaya (Kates; Carica papaya L.), Katu' (Katu'; Sauropus androgynus L.), Pisang (Gedang; Musa paradisiaca L.), Jeruk Nipis (Jeruk Nipis; Citrus aurantifolioa Christm.), Turi Merah (Kembang Turi; Sesbania grandiflora (L.) Poir.), Kenanga (Wongso; Cananga odorata Lam.), Kemiri (Miri; Aleurites moluccana (L.) Willd), Lidah Buaya (Cacap; Aloe vera (L.) Burm. f.) organ yang dimanfaatkan mulai dari umbi, daun, buah, ontong, dan bunga. Proses pembuatannya beragam, mulai dari ditumbuk, direbus, dan dikonsumsi secara langsung. Tumbuhan yang terdiri dari 22 spesies tersebut dimanfaatkan untuk kecantikan/perawatan tubuh berasal dari 16 famili, yaitu Rutacea sebanyak 3 spesies, Zingiberaceae sebanyak 3 spesies, Poace sebanyak 1 spesies, Meliaceae sebanyak 1 spesies, Annonaceae sebanyak 1 spesies, Fabaceae sebanyak 3 spesies, Arecaceae sebanyak 1 spesies, piperaceae sebanyak 1 spesies, Caricaceae sebanyak 1 spesies, Euphorbiaceae sebanyak 2 spesies, Musaceae sebanyak 1 spesies, Asphodelaceae sebanyak 1 spesies, Apocynaceae sebanyak 1 spesies, Rubiace sebanyak 1 spesies, Convolvulaceae sebanyak 1 spesies. Famili Rutaceae adalah pohon atau perdu, jarang semak. Daun berhadapan atau berseling, tunggal atau majemuk dengan kelenjar minyak transparan. Bunga beraturan, berkelamin 2, tandan atau malai. Kelopak berjumlah 4-5, bersatu atau tidak. Mahkota kebanyakan berjumlah 4-5, berdaun lepas. Benang sari 4-5 atau 8-10, kepala sari beruang 2. Tonjolan dasar bunga beringgit atau berlekuk di dalam benang sari. Bakal buah menumpang, seperti juga buahnya dan bentuk sangat berbeda. Buah buni kotak, buni, batu atau buah berbelah, contoh; Jeruk Purut (Jeruk Purut; Citrus hystrix DC), Kemuning (Kemuning; Murraya paniculata L.Â Jack), Jeruk Nipis (Jeruk Nipis; Citrus aurantifolioa Christm.). Famili Zingiberaceae merupakan herba menahun dengan akar rimpang. Batang tegak, daun kerap kali 2 baris dengan pelepah yang memeluk batang dan lidah diantara batas pelepah dan helaian daun. Bunga zygomorph (simetri), berkelamin 2. Kelopak berbentuk tabung dengan ujung yang bertaju, kerapkali terbelah serupa pelepah. Daun 
mahkota 3 pada pangkal melekat. Benang sari sempurna 1, penghubung sari kebanyakan lebar, ruang sari 2. Benang sari serupa daun mahkota dan yang dua lainnya lebih kecil. Bakal buah tenggelam beruang 3 atau 1. Biji menempel, tangkai putik langsing dengan ujung terjepit diantara kedua ruang sari, kepala sari melebar. Buah kotak kebanyakan berkatup 3, contoh; Kencur (Kencur; Kaempferia galanga L.), Kunyit (Kunir; Curcuma longa L.), Kunci (Kunci; Boesenbergia rotunda (L.) Mansf.). Famili Poaceae merupakan tumbuhan rerumputan, batang cylindris agak pipih atau persegi, berlubang atau massif, pada buku selalu massif dan kadang membesar, berbentuk herba atau berkayu (bambu). Daun tunggal 2 baris, pelepah daun berkembang sangat baik pada batas pelepah dan helaian daun kadang terdapat lidah. Helaian daun duduk dan hampir selalu berbentuk lanset atau garis, ibu tulang daun dan beberapa tulang daun sejajar. Bunga tersusun dalam bulir yang terdiri dari daun serupa sisik yang duduknya berseling dalam dua baris yang berhadapan. Bunga hampir selalu berkelamin 2, dan juga ada tidak berkelamin atau kosong. Tangkai putik hampir selalu dua, kepala putik berbentuk bulu atau malai, bakal buah beruang dan berbiji satu, buah tersebut yang dinamakan padi, contoh; Padi (Pari; Oryza sativa L.). Famili Meliaceae merupakan tumbuhan berkayu, jarang herba, berkelenjar damar atau minyak. Daun tersebar tersusun menyirip. Bunga beraturan, kebanyakan berkelamin 2, kelopak bersatu. Daun mahkota lepas dan kadang-kadang bersatu. Daun mahkota lepas dan kadang bersatu. Benang sari sebanyak atau dua kali daun mahkota, tangkai sari kadang melekat menjai tabung. Tonjolan penebalan dasar bunga kadang bentuk tabung. Bakal buah menumpang, kadang setengah tenggelam. Bakal biji biasanya 1-2 per ruang, bentuk buah bermacam-macam, contoh; Lansat (Langsep; Lansium domesticum Corrêa). Famili Annonaceae merupakan pohon, perdu atau liana. Daun berseling tunggal dan tanpa daun penumpu. Bunga beraturan kadang berkelamin 2. Daun kelopak 3 kadang 4, lepas atau melekat. Daun mahkota 6 dalam 2 lingkaran masing-masing 3, kadang lepas atau melekat. Benang sari 3 atau banyak dan pendek. Ruang sari berbentuk garis, bakal buah 1 sampai banyak, menumpang lepas atau melekat, beruang 1, bakal biji 1 sampai banyak. Tangkai putik lepas, kadang pendek bahkan tidak ada. Buah 
duduk atau bertangkai, serupa buah buni atau kering dan berkatup 2, contoh; Kenanga (Wongso; Cananga odorata Lam.). Famili Fabaceae merupakan tumbuhan pohon, perdu atau semak. Daun berseling atau tersebar, menyirip atau menyirip rangkap, daun penumpu ada dan cepat rontok. Bunga berkelamin 2 dalam tandan, malai rata atau malai, kadang zygomorph (simetris). Kelopak berdaun lekat, benang sari 1-50 lepas atau bersatu, kepala sari beruang 2, bakal buah menumpang dan beruang 1. Buah polong, contoh; Asem (Asem; Tamarindus Indica L.), Majakan (Majakan; Quercus lusitanica), Turi Merah (Kembang Turi; Sesbania grandiflora (L.) Poir.). Famili Arecaceae merupakan pohon atau tumbuhan memanjat dengan batang yang tidak bercabang dan mempunyai bekas daun berbentuk cincin, batang yang terletak diatas tanah atau akar rimpang dapat keluar beberapa batang (membentuk rumpun). Daun menyirip atau bentuk kipas, pelepah daun pangkal tangkai daun yang melebar tongkol bunga tumbuh pada ketiak daun, tomgkol muda kadang dikelilingi oleh satu seludang daun atau lebih, tangkai dan cabang samping mempunyai seludang kecil. Bunga duduk pada cabang berdaging tebal, berkelamin tunggal, tenda bunga dalam 2 lingkaran dengan jumlah masingmasing 3, benang sari 6, 9 dan bisa lebih. Daun buah 3, bakal buah beruang 1-3 di tiap ruang 1 bakal biji. Buah buni buah batu, contoh: Pinang (Jambe; Areca catechu L.).

Famili Piperaceae merupakan tumbuhan semak atau perdu, kadang memanjat dengan akar lekat. Daun duduknya berbeda tunggal tepi rata dan bertulang menyirip atau menjari, memiliki bau aromatis atau rasanya pedas. Bunga kecil dan bentuk bulir atau kadang bentuk payung, masing-masing dalam ketiak daun pelindung tanpa perhiasan bunga, berkelamin 2 atau 1. Benang sari 110 ruang sari 2. Bakal buah beruang 1, kepala putik 1-5. Buah buni berbiji 1, contoh; Sirih (Suruh; Piper betle L.). Famili Caricaceae merupakan tumbuhan herba berbentuk pohon dengan daun tunggal atau majemuk menjari, tersebar tanpa daun penumpu, kadang bergetah. Bunga beraturan berkelamin 1 dengan sumbu bunga yang berbentuk lonceng atau tabung. Kelopak bertaju 5 atau tepi rata. Daun mahkota 5, pada bunga jantan bersatu, bunga betina bersatu menjadi 
tabung pendek atau lepas. Benang sari 10. Bakal buah menumpang. Tangkai putik lepas, buah buni, contoh; Pepaya (Kates; Carica papaya L.).

Famili Euphorbiaceae merupakan tumbuhan pohon, perdu, semak, kadangkadang berair dan kadang bergetah. Daun tersebar dan kadang berhadapan, tunggal atau majemuk menjari dengan daun penumpu. Ujung tangkai daun atau pangkal helaian daun terdapat kelenjar. Bunga berkelamin 1, berumah 1 atau 2, bunga betina dan jantan kadang-kadang berbeda besar. Tenda bunga tunggal atau rangkap, kadang-kadang tidak ada. Tonjolan menebal, benang sari 1 sampai banyak, lepas dan melekat. Bakal buah menumpang beruang 2-4. Bakal biji 1-2 beruang. Buah bermacam-macam, contoh; Katu' (Katu'; Sauropus androgynus L.), Kemiri (Miri; Aleurites moluccana (L.) Willd). Famili Musaceae merupakan semak atau pohon kadang dengan batang semu yang terdiri dari pelepah daun. Daun 2 baris atau dalam spiral, dengan pelepah yang tumbuh sempurna, bertulang dan menyirip, dengan tulang daun lateral yang banyak dan sejajar. Karangan bunga berbunga banyak. Masingmasing berupa zygomorph (Simetri) berkelamin 2 atau 1 dan kadang tidak berkelamin. Daun tenda bunga hampir selalu 6 . Benang sari hampir selalu 5, kepala sari 2 ruang. Bakal buah tenggelam, beruang 3, ruang bakal biji 1 sampai banyak. Buah buni atau buah kotak tanpa biji, contoh; Pisang (Gedang; Musa paradisiaca L.).

Famili Apocynaceae merupakan tumbuhan berupa pohon, perdu atau semak, sering memanjat dan bergetah. Daun tunggal seluruhnya berhadapan atau dalam karangan, tanpa daun penumpu, bertepi rata. Bunga dalam anak payung dengan malai rata, jarang berdiri sendiri, beraturan, berkelamin 2. Kelopak kebanyakan berbagi 5 atau bercangap 5, mahkota berdaun lekat dengan letak yang terputar. Benang sari tertancap pada tabung mahkota berseling dengan lekukan. Kepala sari beruang 2. Tonjolan dasar bunga biasanya tidak ada. Bakal buah kebanyakan 2, terpisah tetapi dihubungkan dengan tangkai putik, beruang 1 dan jarang berlekatan sampai satu bakal buah yang beruang 1 atau 2. Tangkai putik 1, kepala putik bergigi 2. Buah batu atau buah bumbung dan kadang buah kotak, contoh; Santan (Santen; Kibatalia arborea (Blume) G. Don). Famili Rubiaceae merupakan tumbuhan berupa pohon perdu atau herba, kadang-kadang memanjat dengan daun bersilang berhadapan atau kadang berkarang. Daun kebanyakan bertepi rata. Daun penumpu terletak antara tangkai daun, berlekatan berpasangan. Bunga di ketiak atau terminal, kadang tunggal, kebanyakan dalam berbagai 
bentuk karangan bunga beraturan, berkelamin 2, kelopak dan mahkota berdaun lekat. Benang sari sama banyak berseling dan tertancap pada tabung atau leher mahkota. Kepala sari beruang. Bakal buah seluruhnya atau sebagian besar tenggelam, beruang sampai banyak. Tangkai putik 1. Buah sangat bermacammacam; buah kotak, buah buni, buha batu. Biji 1 sampai banyak dalam ruang, contoh; Gambir (Gambir; Uncaria gambir (Hunter) Roxb.). Famili convolvulaceae merupakan tumbuhan semak atau tumbuhan berkayu, kebanyakan tumbuh membelit, bergetah. Batang tebal dan berongga. Daun tersebar tunggal dan kadang tanpa daun penumpu. Bunga kebanyakan beraturan berkelamin 2 . Kelopak berdaun lepas, mahkota berdaun lekat. Benang sari berseling, bakal buah menumpang beruang 2-5, tangkai putik 1 atau 2. Buah kotak dengan biji sedikit. Tanpa umbi dalam tanah, contoh; Kangkung (Kangkung; Ipomoea aquatica Forssk.).

\section{KESIMPULAN}

Ditemukan 125 spesies tumbuhan bermanfaat yang masih digunakan sebagai pengobatan tradisional, bahan makanan dan penyedap, bahan bangunan, ritual adat, pewarna alami, dan kecantikan/perawatan tubuh. Salah satunya dimanfaatkan sebagai bahan kecantikan/perawatan tubuh yang terdapat 22 spesies.

\section{KEPUSTAKAAN}

Wahyu, 2015, Pemanfaatan Tumbuhan Sebagai Bahan Kosmetik Oleh Suku Melayu Di Kecamatan Sungai Pinyuh Kabupaten Mempawah, Jurusan Biologi, Skripsi, Fakultas Matematika \& Ilmu Pengetahuan Alam, Universitas Tanjungpura, Pontianak.

Evi, Linda Riza, 2017, Studi Etnobotani Tumbuhan Kosmetik Alami Masyarakat Suku Dayak Kanayatn Desa Sebatih Kecamatan Sengah Temila Kabupaten Landak. No. 7 : 61-68. 